\title{
Existence theorems for single-valued and set-valued mappings with $w$-distances in metric spaces
}

\author{
Soh Kaneko', Wataru Takahashi ${ }^{2,3,4}$, Ching-Feng Wen² and Jen-Chih Yao ${ }^{5^{*}}$
}

"Correspondence:

yaojc@mail.cmu.edu.tw

${ }^{5}$ Center for General Education,

China Medical University, Taichung,

40402, Taiwan

Full list of author information is

available at the end of the article

\section{Springer}

\begin{abstract}
In this paper, using the concept of $w$-distances, and we prove existence theorems for single-valued mappings and set-valued mappings in a complete metric space which generalize Takahashi, Wong, and Yao's theorems.
\end{abstract}

MSC: Primary 47H10; secondary 37C25; 58J20

Keywords: complete metric space; contractive mapping; fixed point theorem; generalized hybrid mapping; $w$-distance

\section{Introduction}

Let $\ell^{\infty}$ be the Banach space of bounded sequences with supremum norm and let $\left(\ell^{\infty}\right)^{*}$ be the dual space of $\ell^{\infty}$. Let $\mu$ be an element of $\left(\ell^{\infty}\right)^{*}$. We denote by $\mu(f)$ the value of $\mu$ at $f=\left\{x_{n}\right\} \in \ell^{\infty}$. Sometimes, we denote by $\mu_{n}\left(x_{n}\right)$ the value $\mu(f)$. A linear functional $\mu$ on $\ell^{\infty}$ is called a mean if $\mu(e)=\|\mu\|=1$, where $e=\{1,1,1, \ldots\}$. Hasegawa et al. [1] obtained the following unique fixed point theorem on a complete metric space.

Theorem 1.1 ([1]) Let $(X, d)$ be a complete metric space and let $S$ be a mapping of $X$ into itself. Let $\ell^{\infty}$ be the Banach space of bounded sequences with the supremum norm. Suppose that there exist a real number $r$ with $0 \leq r<1$ and an element $x \in X$ such that $\left\{S^{n} x\right\}$ is bounded and

$$
\mu_{n} d\left(S^{n} x, S y\right) \leq r \mu_{n} d\left(S^{n} x, y\right), \quad \forall y \in X
$$

for some mean $\mu$ on $l^{\infty}$. Then the following hold:

(1) S has a unique fixed point $u \in X$;

(2) for every $z \in X$, the sequence $\left\{S^{n} z\right\}$ converges to $u$.

By using the idea of Caristi's fixed point theorem [2], Chuang et al. [3] proved a unique fixed point theorem for single-valued mappings which generalizes Theorem 1.1. Furthermore, they obtained an existence theorem for set-valued mappings in a complete metric space. Using these results, Chuang et al. [3] obtained new and well-known existence theorems in a complete metric space.

(c) 2016 Kaneko et al. This article is distributed under the terms of the Creative Commons Attribution 4.0 International License (http://creativecommons.org/licenses/by/4.0/), which permits unrestricted use, distribution, and reproduction in any medium, provided you give appropriate credit to the original author(s) and the source, provide a link to the Creative Commons license, and indicate if changes were made. 
On the other hand, in 1996, Kada et al. [4] introduced the concept of $w$-distances on a metric space.

Let $(X, d)$ be a metric space. A function $p: X \times X \rightarrow[0, \infty)$ is said to be a $w$-distance [4] on $X$ if the following are satisfied:

(1) $p(x, z) \leq p(x, y)+p(y, z)$ for all $x, y, z \in X$;

(2) for any $x \in X, p(x, \cdot): X \rightarrow[0, \infty)$ is lower semicontinuous;

(3) for any $\varepsilon>0$, there exists $\delta>0$ such that $p(z, x) \leq \delta$ and $p(z, y) \leq \delta$ imply $d(x, y) \leq \varepsilon$.

Using the concept of $w$-distances, they improved important results in complete metric spaces. For example, they improved Caristi's fixed point theorem [2], Ekeland's variational principle [5] and the nonconvex minimization theorem according to Takahashi [6]. Motivated by Chuang et al. [3], Takahashi et al. [7] improved their unique fixed point theorem for single-valued mappings by using the concept of $w$-distances. Furthermore, they extended Chuang et al.'s existence theorem [3] for set-valued mappings to $w$-distances. However, Takahashi et al. [7] assumed that $w$-distances are symmetric.

In this paper, without assuming that $w$-distances are symmetric, we prove Takahashi et al.'s unique fixed point theorems for single-valued mappings and their existence theorem for set-valued mappings in a complete metric space. Using these results, we obtained new and well-known existence theorems in a complete metric space. In particular, using this unique fixed point theorem for single-valued mappings, we obtain a unique fixed point theorem of Caristi's type [2] with lower semicontinuous functions and $w$-distances. It seems that the proofs are technical and useful.

\section{Preliminaries}

Throughout this paper, we denote by $\mathbb{N}$ and $\mathbb{R}$ the sets of positive integers and real numbers, respectively. Let $X$ be a metric space with metric $d$. Then we denote by $W(X)$ the set of all $w$-distances on $X$. A $w$-distance $p$ on $X$ is called symmetric if $p(x, y)=p(y, x)$ for all $x, y \in X$. We denote by $W_{0}(X)$ the set of all symmetric $w$-distances on $X$. Note that the metric $d$ is an element of $W_{0}(X)$. We also know that there are many important examples of $w$-distances on $X$; see $[4,8]$.

The following lemma was proved by Kada et al. [4]; see also Shioji et al. [9].

Lemma 2.1 ([4]) Let $(X, d)$ be a complete metric space and let $p$ be a $w$-distance on $X$. Let $\left\{x_{n}\right\}$ and $\left\{y_{n}\right\}$ be sequences in $X$. Let $\left\{s_{n}\right\}$ and $\left\{t_{n}\right\}$ be sequences in $[0, \infty)$ converging to 0 , and let $x, y, z \in X$. Then the following hold:

(1) If $p\left(x_{n}, y\right) \leq s_{n}$ and $p\left(x_{n}, z\right) \leq t_{n}$ for all $n \in \mathbb{N}$, then $y=z$. In particular, if $p(x, y)=0$ and $p(x, z)=0$, then $y=z$;

(2) if $p\left(x_{n}, y_{n}\right) \leq s_{n}$ and $p\left(x_{n}, z\right) \leq t_{n}$ for all $n \in \mathbb{N}$, then the sequence $\left\{y_{n}\right\}$ converges to $z$;

(3) if $p\left(x_{n}, x_{m}\right) \leq s_{n}$ for all $n, m \in \mathbb{N}$ with $m>n$, then the sequence $\left\{x_{n}\right\}$ is a Cauchy sequence;

(4) if $p\left(y, x_{n}\right) \leq s_{n}$ for all $n \in \mathbb{N}$, then $\left\{x_{n}\right\}$ is a Cauchy sequence.

Let $(X, d)$ be a metric space and let $g$ be a function of $X$ into $(-\infty, \infty]=\mathbb{R} \cup\{\infty\}$. Then $g$ is proper if there exists $x \in X$ such that $g(x)<\infty$. A function $g$ is lower semicontinuous if for any $t \in \mathbb{R}$, the set $\{x \in X: g(x) \leq t\}$ is closed. A function $g$ is bounded below if there exists $K \in \mathbb{R}$ such that

$$
K \leq g(x), \quad \forall x \in X
$$


Kada et al. [4] improved Caristi's fixed point theorem [2] as follows; see also [8], Theorem 2.2.8.

Theorem 2.2 ([4]) Let $(X, d)$ be a complete metric space, $p \in W(X)$, and let $\phi: X \rightarrow$ $(\infty, \infty]$ be a proper, bounded below, and lower semicontinuous function. Let $T: X \rightarrow X$ be a mapping such that for each $x \in X$,

$$
p(x, T x)+\phi(T x) \leq \phi(x) .
$$

Then there exists $z \in X$ such that $T z=z$ and $p(z, z)=0$.

A mean $\mu$ is called a Banach limit on $\ell^{\infty}$ if $\mu_{n}\left(x_{n+1}\right)=\mu_{n}\left(x_{n}\right)$ for all $\left\{x_{n}\right\} \in \ell^{\infty}$. We know that there exists a Banach limit on $\ell^{\infty}$. If $\mu$ is a Banach limit on $\ell^{\infty}$, then for $f=\left\{x_{n}\right\} \in \ell^{\infty}$,

$$
\liminf _{n \rightarrow \infty} x_{n} \leq \mu_{n}\left(x_{n}\right) \leq \limsup _{n \rightarrow \infty} x_{n}
$$

In particular, if $f=\left\{x_{n}\right\} \in \ell^{\infty}$ and $x_{n} \rightarrow a \in \mathbb{R}$, then we have $\mu(f)=\mu_{n}\left(x_{n}\right)=a$. For the proof of existence of a Banach limit and its other elementary properties, see [8].

\section{Existence theorems for single-valued mappings}

In this section, using means and $w$-distances, we first prove an existence theorem for mappings in metric spaces which generalizes Takahashi et al. [7].

Theorem 3.1 Let $(X, d)$ be a complete metric space, let $p \in W(X)$ and let $\left\{x_{n}\right\}$ be a sequence in $X$ such that $\left\{p\left(x_{n}, w\right)\right\}$ and $\left\{p\left(w, x_{n}\right)\right\}$ are bounded for some $w \in X$. Let $\mu$ be a mean on $\ell^{\infty}$ and let $\phi: X \rightarrow(-\infty, \infty]$ be a proper, bounded below, and lower semicontinuous function. Let $S: X \rightarrow X$ be a mapping. Suppose that there exist $l, m \in \mathbb{N} \cup\{0\}$ such that

$$
\mu_{n} p\left(x_{n}, S^{l} y\right)+\mu_{n} p\left(S^{m} y, x_{n}\right)+\phi(S y) \leq \phi(y)
$$

for all $y \in X$. Then there exists $x_{0} \in X$ such that

(1) $x_{0}$ is a unique fixed point of $S$ in $\{x \in X: \phi(x)<\infty\}$;

(2) $x_{0}=\lim _{k \rightarrow \infty} S^{k} y$ for all $y \in X$ with $\phi(y)<\infty$;

(3) $\phi\left(x_{0}\right)=\inf _{v \in X} \phi(v)$.

Proof Since $\left\{p\left(x_{n}, w\right)\right\}$ is bounded for some $w \in X$, we have, for any $y \in X,\left\{p\left(x_{n}, y\right)\right\}$ is bounded. In fact, we have, for any $n \in \mathbb{N}$,

$$
p\left(x_{n}, y\right) \leq p\left(x_{n}, w\right)+p(w, y) \leq \sup _{k \in \mathbb{N}} p\left(x_{k}, w\right)+p(w, y)
$$

Furthermore, since $\left\{p\left(w, x_{n}\right)\right\}$ is bounded, we see that $\left\{p\left(z, x_{n}\right)\right\}$ is bounded for all $z \in X$. In fact, we have, for any $n \in \mathbb{N}$,

$$
p\left(z, x_{n}\right) \leq p(z, w)+p\left(w, x_{n}\right) \leq p(z, w)+\sup _{k \in \mathbb{N}} p\left(w, x_{k}\right)
$$


We have from (3.1)

$$
\mu_{n} p\left(x_{n}, S^{l} y\right)+\phi(S y) \leq \phi(y) \quad \text { and } \quad \mu_{n} p\left(S^{m} y, x_{n}\right)+\phi(S y) \leq \phi(y)
$$

for all $y \in X$. For $y \in X$ with $\phi(y)<\infty$, we have from (3.2) $\phi\left(S^{k} y\right)<\infty$ for all $k \in \mathbb{N} \cup\{0\}$ and hence

$$
\mu_{n} p\left(x_{n}, S^{l} S^{k} y\right) \leq \phi\left(S^{k} y\right)-\phi\left(S^{k+1} y\right)
$$

and

$$
\mu_{n} p\left(S^{m} S^{k} y, x_{n}\right) \leq \phi\left(S^{k} y\right)-\phi\left(S^{k+1} y\right) .
$$

Then we see that $\left\{\phi\left(S^{k} y\right)\right\}$ is a decreasing sequence which is bounded below. Hence $\lim _{k \rightarrow \infty} \phi\left(S^{k} y\right)$ exists. Put $s=\lim _{k \rightarrow \infty} \phi\left(S^{k} y\right)$. Since

$$
\mu_{n} p\left(x_{n}, S^{l+k} y\right) \leq \phi\left(S^{k} y\right)-\phi\left(S^{k+1} y\right) \leq \phi\left(S^{k} y\right)-s
$$

and

$$
\mu_{n} p\left(S^{m+k} y, x_{n}\right) \leq \phi\left(S^{k} y\right)-\phi\left(S^{k+1} y\right) \leq \phi\left(S^{k} y\right)-s
$$

for all $k \in \mathbb{N}$, we have

$$
\limsup _{k \rightarrow \infty} \mu_{n} p\left(x_{n}, S^{l+k} y\right) \leq 0 \quad \text { and } \quad \limsup _{k \rightarrow \infty} \mu_{n} p\left(S^{m+k} y, x_{n}\right) \leq 0 .
$$

Then we have

$$
\lim _{k \rightarrow \infty} \mu_{n} p\left(x_{n}, S^{l+k} y\right)=0 \text { and } \lim _{k \rightarrow \infty} \mu_{n} p\left(S^{m+k} y, x_{n}\right)=0 .
$$

We have, for any $k, n \in \mathbb{N}$,

$$
p\left(S^{l+m+k} y, S^{l+m+k+1} y\right) \leq p\left(S^{l+m+k} y, x_{n}\right)+p\left(x_{n}, S^{l+m+k+1} y\right) .
$$

Since $\mu$ is a mean on $\ell^{\infty}$, we have from (3.3) and (3.4), for any $k \in \mathbb{N}$,

$$
\begin{aligned}
p\left(S^{l+m+k} y, S^{l+m+k+1} y\right) & \leq \mu_{n} p\left(S^{l+m+k} y, x_{n}\right)+\mu_{n} p\left(x_{n}, S^{l+m+k+1} y\right) \\
& \leq \phi\left(S^{l+k} y\right)-\phi\left(S^{l+k+1} y\right)+\phi\left(S^{m+k+1} y\right)-\phi\left(S^{m+k+2} y\right) .
\end{aligned}
$$

We have from (3.6), for any $h, k \in \mathbb{N}$ with $k>h$,

$$
\begin{aligned}
p\left(S^{l+m+h} y, S^{l+m+k} y\right) \leq & p\left(S^{l+m+h} y, S^{l+m+h+1} y\right) \\
& +p\left(S^{l+m+h+1} y, S^{l+m+h+2} y\right)+\cdots+p\left(S^{l+m+k-1} y, S^{l+m+k} y\right) \\
\leq & \phi\left(S^{l+h} y\right)-\phi\left(S^{l+h+1} y\right)+\phi\left(S^{m+h+1} y\right)-\phi\left(S^{m+h+2} y\right)
\end{aligned}
$$




$$
\begin{aligned}
& +\phi\left(S^{l+h+1} y\right)-\phi\left(S^{l+h+2} y\right)+\phi\left(S^{m+h+2} y\right)-\phi\left(S^{m+h+3} y\right)+\cdots \\
& +\phi\left(S^{l+k-1} y\right)-\phi\left(S^{l+k} y\right)+\phi\left(S^{m+k} y\right)-\phi\left(S^{m+k+1} y\right) \\
= & \phi\left(S^{l+h} y\right)-\phi\left(S^{l+k} y\right)+\phi\left(S^{m+h+1} y\right)-\phi\left(S^{m+k+1} y\right) \\
\leq & \phi\left(S^{l+h} y\right)-s+\phi\left(S^{m+h+1} y\right)-s \\
\leq & \phi\left(S^{l+h} y\right)-s+\phi\left(S^{m+h} y\right)-s \\
= & \alpha_{h}-s+\beta_{h}-s
\end{aligned}
$$

where $\alpha_{h}=\phi\left(S^{l+h} y\right)$ and $\beta_{h}=\phi\left(S^{m+h} y\right)$. Since $\alpha_{h}-s+\beta_{h}-s \rightarrow 0$ as $h \rightarrow \infty$, we see from Lemma 2.1 that $\left\{S^{l+m+k} y\right\}$ is a Cauchy sequence in $X$. Since $X$ is complete, there exists $y_{0} \in X$ such that $\lim _{k \rightarrow \infty} S^{l+m+k} y=y_{0}$. We know from the definition of $p$ that, for any $n \in \mathbb{N}$, $y \mapsto p\left(x_{n}, y\right)$ is lower semicontinuous. Using this and following the technique of [7], we have, for any $n \in \mathbb{N}$,

$$
p\left(x_{n}, y_{0}\right) \leq \liminf _{k \rightarrow \infty} p\left(x_{n}, S^{l+m+k} y\right)
$$

and hence

$$
\mu_{n} p\left(x_{n}, y_{0}\right) \leq \mu_{n}\left(\liminf _{k \rightarrow \infty} p\left(x_{n}, S^{l+m+k} y\right)\right) .
$$

On the other hand, we have from (3.7), for any $h, k, n \in \mathbb{N}$ with $k>h$,

$$
p\left(x_{n}, S^{l+m+k} y\right) \leq p\left(x_{n}, S^{l+m+h} y\right)+p\left(S^{l+m+h} y, S^{l+m+k} y\right) \leq p\left(x_{n}, S^{l+m+h} y\right)+\alpha_{h}-s+\beta_{h}-s
$$

and hence

$$
\limsup _{k \rightarrow \infty} p\left(x_{n}, S^{l+m+k} y\right) \leq p\left(x_{n}, S^{l+m+h} y\right)+\alpha_{h}-s+\beta_{h}-s .
$$

Applying $\mu$ to both sides of the inequality, we have

$$
\mu_{n}\left(\limsup _{k \rightarrow \infty} p\left(x_{n}, S^{l+m+k} y\right)\right) \leq \mu_{n} p\left(x_{n}, S^{l+m+h} y\right)+\alpha_{h}-s+\beta_{h}-s .
$$

Letting $h \rightarrow \infty$, we get from (3.5) that

$$
\begin{aligned}
\mu_{n}\left(\limsup _{k \rightarrow \infty} p\left(x_{n}, S^{l+m+k} y\right)\right) & \leq \liminf _{h \rightarrow \infty} \mu_{n} p\left(x_{n}, S^{l+m+h} y\right)+0 \\
& =\lim _{h \rightarrow \infty} \mu_{n} p\left(x_{n}, S^{l+m+h} y\right) \\
& =0 .
\end{aligned}
$$

Then we have from (3.8) and (3.9)

$$
\begin{aligned}
\mu_{n} p\left(x_{n}, y_{0}\right) & \leq \mu_{n}\left(\liminf _{k \rightarrow \infty} p\left(x_{n}, S^{l+m+k} y\right)\right) \\
& \leq \mu_{n}\left(\limsup _{k \rightarrow \infty} p\left(x_{n}, S^{l+m+k} y\right)\right)
\end{aligned}
$$




$$
\begin{aligned}
& \leq \lim _{k \rightarrow \infty} \mu_{n} p\left(x_{n}, S^{l+m+k} y\right) \\
& =0 .
\end{aligned}
$$

This implies that

$$
\mu_{n} p\left(x_{n}, y_{0}\right)=0 .
$$

Similarly, for another $u \in X$ with $\phi(u)<\infty$, there exists $u_{0} \in X$ such that $\lim _{k \rightarrow \infty} S^{l+m+k} u=$ $u_{0}$ and $\mu_{n} p\left(x_{n}, u_{0}\right)=0$. We also have, for $k, n \in \mathbb{N}$,

$$
p\left(S^{l+m+k} y, y_{0}\right) \leq p\left(S^{l+m+k} y, x_{n}\right)+p\left(x_{n}, y_{0}\right)
$$

and hence

$$
\begin{aligned}
p\left(S^{l+m+k} y, y_{0}\right) & \leq \mu_{n} p\left(S^{l+m+k} y, x_{n}\right)+\mu_{n} p\left(x_{n}, y_{0}\right) \\
& =\mu_{n} p\left(S^{l+m+k} y, x_{n}\right)+0 \\
& =\mu_{n} p\left(S^{l+m+k} y, x_{n}\right) .
\end{aligned}
$$

Furthermore, we have, for $k, n \in \mathbb{N}$,

$$
p\left(S^{l+m+k} y, u_{0}\right) \leq p\left(S^{l+m+k} y, x_{n}\right)+p\left(x_{n}, u_{0}\right)
$$

and hence

$$
\begin{aligned}
p\left(S^{l+m+k} y, u_{0}\right) & \leq \mu_{n} p\left(S^{l+m+k} y, x_{n}\right)+\mu_{n} p\left(x_{n}, u_{0}\right) \\
& =\mu_{n} p\left(S^{l+m+k} y, x_{n}\right)+0 \\
& =\mu_{n} p\left(S^{l+m+k} y, x_{n}\right) .
\end{aligned}
$$

We know that $\mu_{n} p\left(S^{l+m+k} y, x_{n}\right) \rightarrow 0$ as $k \rightarrow \infty$. Thus, we have from (3.11), (3.12), and Lemma $2.1 y_{0}=u_{0}$. Therefore we have $x_{0}=\lim _{k \rightarrow \infty} S^{k} z$ for all $z \in X$ with $\phi(z)<\infty$. Since $\phi$ is lower semicontinuous and $\lim _{k \rightarrow \infty} S^{k} z=x_{0}$ for all $z \in X$ with $\phi(z)<\infty$, we have

$$
\phi\left(x_{0}\right) \leq \liminf _{k \rightarrow \infty} \phi\left(S^{k} z\right)=\lim _{k \rightarrow \infty} \phi\left(S^{k} z\right)=\inf _{k \in \mathbb{N} \cup\{0\}} \phi\left(S^{k} z\right) \leq \phi(z) .
$$

This implies that

$$
\phi\left(x_{0}\right)=\inf _{y \in X} \phi(y) .
$$

We finally prove that $x_{0}$ is a unique fixed point of $S$ in $\{x \in X: \phi(x)<\infty\}$. Since, from (3.13),

$$
0 \leq \mu_{n} p\left(x_{n}, S^{l} x_{0}\right) \leq \phi\left(x_{0}\right)-\phi\left(S x_{0}\right) \leq 0,
$$


we have $\mu_{n} p\left(x_{n}, S^{l} x_{0}\right)=0$. We also know $\mu_{n} p\left(x_{n}, x_{0}\right)=0$. For $k, n \in \mathbb{N}$, we have

$$
p\left(S^{k} S^{m} y, S^{l} x_{0}\right) \leq p\left(S^{k} S^{m} y, x_{n}\right)+p\left(x_{n}, S^{l} x_{0}\right)
$$

and

$$
p\left(S^{k} S^{m} y, x_{0}\right) \leq p\left(S^{k} S^{m} y, x_{n}\right)+p\left(x_{n}, x_{0}\right)
$$

Then, as in the above argument, we have

$$
\begin{aligned}
p\left(S^{k} S^{m} y, S^{l} x_{0}\right) & \leq \mu_{n} p\left(S^{k} S^{m} y, x_{n}\right)+\mu_{n} p\left(x_{n}, S^{l} x_{0}\right) \\
& =\mu_{n} p\left(S^{k} S^{m} y, x_{n}\right)
\end{aligned}
$$

and

$$
\begin{aligned}
p\left(S^{k} S^{m} y, x_{0}\right) & \leq \mu_{n} p\left(S^{k} S^{m} y, x_{n}\right)+\mu_{n} p\left(x_{n}, x_{0}\right) \\
& =\mu_{n} p\left(S^{k} S^{m} y, x_{n}\right) .
\end{aligned}
$$

We also know from (3.5) that $\mu_{n} p\left(S^{m+k} y, x_{n}\right) \rightarrow 0$ as $k \rightarrow \infty$. Therefore, from (3.14), (3.15), and Lemma $2.1 S^{l} x_{0}=x_{0}$. Using $S^{l} x_{0}=x_{0}$, we have from (3.13)

$$
\begin{aligned}
0 & \leq \mu_{n} p\left(x_{n}, S x_{0}\right)=\mu_{n} p\left(x_{n}, S^{l+1} x_{0}\right) \\
& \leq \phi\left(S x_{0}\right)-\phi\left(S^{2} x_{0}\right) \\
& \leq \phi\left(x_{0}\right)-\phi\left(S^{2} x_{0}\right) \leq 0
\end{aligned}
$$

and hence $\mu_{n} p\left(x_{n}, S x_{0}\right)=0$. Since, for $k, n \in \mathbb{N}$,

$$
p\left(S^{k} S^{m} y, S x_{0}\right) \leq p\left(S^{k} S^{m} y, x_{n}\right)+p\left(x_{n}, S x_{0}\right),
$$

we have

$$
\begin{aligned}
p\left(S^{k} S^{m} y, S x_{0}\right) & \leq \mu_{n} p\left(S^{k} S^{m} y, x_{n}\right)+\mu_{n} p\left(x_{n}, S x_{0}\right) \\
& =\mu_{n} p\left(S^{k} S^{m} y, x_{n}\right) .
\end{aligned}
$$

We have from (3.15), (3.16), and Lemma $2.1 S x_{0}=x_{0}$. We show that $x_{0}$ is a unique fixed point of $S$ in $\{x \in X: \phi(x)<\infty\}$. Indeed, if $z_{0}$ is a fixed point of $S$ with $\phi\left(z_{0}\right)<\infty$, then

$$
0 \leq \mu_{n} p\left(x_{n}, z_{0}\right)=\mu_{n} p\left(x_{n}, S^{l} z_{0}\right) \leq \phi\left(z_{0}\right)-\phi\left(S z_{0}\right)=\phi\left(z_{0}\right)-\phi\left(z_{0}\right)=0
$$

and hence $\mu_{n} p\left(x_{n}, z_{0}\right)=0$. Since, for $k, n \in \mathbb{N}$,

$$
p\left(S^{k} S^{m} y, z_{0}\right) \leq p\left(S^{k} S^{m} y, x_{n}\right)+p\left(x_{n}, z_{0}\right),
$$

we have

$$
p\left(S^{k} S^{m} y, z_{0}\right) \leq \mu_{n} p\left(S^{k} S^{m} y, x_{n}\right)+\mu_{n} p\left(x_{n}, z_{0}\right)=\mu_{n} p\left(S^{k} S^{m} y, x_{n}\right) .
$$


Since $\mu_{n} p\left(S^{m+k} y, x_{n}\right) \rightarrow 0$ as $k \rightarrow \infty$, from (3.15), (3.17), and Lemma 2.1, we have $z_{0}=x_{0}$. Therefore $x_{0}$ is a unique fixed point of $S$ in $\{y \in X: \phi(y)<\infty\}$. This completes the proof.

Using Theorem 3.1, we can obtain the following result proved by Takahashi et al. [7].

Theorem 3.2 ([7]) Let $(X, d)$ be a complete metric space, let $p \in W_{0}(X)$ and let $\left\{x_{n}\right\}$ be a sequence in $X$ such that $\left\{p\left(x_{n}, x\right)\right\}$ is bounded for some $x \in X$. Let $\mu$ be a mean on $\ell^{\infty}$ and let $\psi: X \rightarrow(-\infty, \infty]$ be a proper, bounded below, and lower semicontinuous function. Let $T: X \rightarrow X$ be a mapping. Suppose that there exists $m \in \mathbb{N} \cup\{0\}$ such that

$$
\mu_{n} p\left(x_{n}, T^{m} y\right)+\psi(T y) \leq \psi(y), \quad \forall y \in X
$$

Then there exists $\bar{x} \in X$ such that

(a) $\bar{x}=\lim _{k \rightarrow \infty} T^{k} y$ for all $y \in X$ with $\psi(y)<\infty$;

(b) $\psi(\bar{x})=\inf _{u \in X} \psi(u)$;

(c) $\bar{x}$ is a unique fixed point of $T$ in $\{x \in X: \psi(x)<\infty\}$.

Proof Since $\left\{x_{n}\right\}$ is a bounded sequence in $X$ such that $\left\{p\left(x_{n}, x\right)\right\}$ is bounded for some $x \in X$, we see from $p \in W_{0}(X)$ that $\left\{p\left(x, x_{n}\right)\right\}$ is bounded. Putting $S=T, l=m$, and $\phi=2 \psi$ in Theorem 3.1, we have

$$
2 \mu_{n} p\left(T^{m} y, x_{n}\right)+2 \psi(T y) \leq 2 \psi(y), \quad \forall y \in X
$$

and hence

$$
\mu_{n} p\left(T^{m} y, x_{n}\right)+\psi(T y) \leq \psi(y), \quad \forall y \in X
$$

Thus we have the desired result from Theorem 3.1.

Using Theorem 3.1 and the generalized Caristi's fixed point theorem (Theorem 2.2), we also have a unique fixed point theorem of Caristi's type [2] with lower semicontinuous functions and $w$-distances.

Theorem 3.3 Let $(X, d)$ be a complete metric space and let $p \in W(X)$ such that $p(x, x)=0$ for all $x \in X$. Let $\phi: X \rightarrow(-\infty, \infty]$ be a proper, bounded below, and lower semicontinuous function. Let $S: X \rightarrow X$ be a mapping. Suppose that there exists $\alpha \in \mathbb{R}$ such that

$$
\alpha(p(S x, y)+p(y, S x))+(1-\alpha)(p(x, y)+p(y, x))+\phi(S y) \leq \phi(y), \quad \forall x, y \in X
$$

Then there exists $x_{0} \in X$ such that

(1) $x_{0}$ is a unique fixed point of $S$ in $\{x \in X: \phi(x)<\infty\}$;

(2) $x_{0}=\lim _{k \rightarrow \infty} S^{k} y$ for all $y \in X$ with $\phi(y)<\infty$;

(3) $\phi\left(x_{0}\right)=\inf _{v \in X} \phi(v)$.

Proof Let us first consider $\alpha>0$. Putting $y=x$ in (3.19), we have from $p(x, x)=0$

$$
\alpha(p(S x, x)+p(x, S x))+\phi(S x) \leq \phi(x), \quad \forall x \in X
$$


and hence

$$
\alpha p(x, S x)+\phi(S x) \leq \phi(x), \quad \forall x \in X
$$

By Theorem 2.2, there exists $u_{0} \in X$ such that $S u_{0}=u_{0}$. Putting $x=u_{0}$ in (3.19) again, we have, for any $y \in X$,

$$
\alpha\left(p\left(S u_{0}, y\right)+p\left(y, S u_{0}\right)\right)+(1-\alpha)\left(p\left(u_{0}, y\right)+p\left(y, u_{0}\right)\right)+\phi(S y) \leq \phi(y) .
$$

Since $S u_{0}=u_{0}$, we have, for any $y \in X$,

$$
p\left(u_{0}, y\right)+p\left(y, u_{0}\right)+\phi(S y) \leq \phi(y) .
$$

By Theorem 3.1, we see that $x_{0}$ is a unique fixed point of $S$ in $\{x \in X: \phi(x)<\infty\}$ such that $\phi\left(x_{0}\right)=\inf _{u \in X} \phi(u)$ and $x_{0}=\lim _{k \rightarrow \infty} S^{k} z$ for all $z \in X$ with $\phi(z)<\infty$.

Next let us consider the case of $\alpha=0$. Then we have

$$
p(x, y)+p(y, x)+\phi(S y) \leq \phi(y), \quad \forall x, y \in X .
$$

Replacing $x$ and $y$ by $S x$ and $x$ in (3.20), respectively, we have

$$
p(S x, x)+p(x, S x)+\phi(S x) \leq \phi(x), \quad \forall x \in X
$$

and hence

$$
p(x, S x)+\phi(S x) \leq \phi(x), \quad \forall x \in X
$$

We also see from Theorem 2.2 that there exists $u_{0} \in X$ such that $S u_{0}=u_{0}$. Putting $x=u_{0}$ in (3.19), we have also

$$
p\left(u_{0}, y\right)+p\left(y, u_{0}\right)+\phi(S y) \leq \phi(y), \quad \forall y \in X .
$$

By Theorem 3.1, we see that $x_{0}$ is a unique fixed point of $S$ in $\{x \in X: \phi(x)<\infty\}$ such that $\phi\left(x_{0}\right)=\inf _{u \in X} \phi(u)$ and $x_{0}=\lim _{k \rightarrow \infty} S^{k} z$ for all $z \in X$ with $\phi(z)<\infty$.

In the case of $\alpha<0$, we have $1-\alpha>0$. Furthermore, replacing $y$ by $S x$ in (3.19), we have from $p(S x, S x)=0$

$$
(1-\alpha)(p(x, S x)+p(S x, x))+\phi\left(S^{2} x\right) \leq \phi(S x), \quad \forall x \in X
$$

and hence

$$
(1-\alpha) p(x, S x)+\phi\left(S^{2} x\right) \leq \phi(S x), \quad \forall x \in X
$$

Take $x \in X$ with $\phi(x)<\infty$. Then we have, for any $n \in \mathbb{N}$,

$$
(1-\alpha) p(x, S x)+\phi\left(S^{2} x\right) \leq \phi(S x)
$$




$$
\begin{aligned}
& (1-\alpha) p\left(S x, S^{2} x\right)+\phi\left(S^{3} x\right) \leq \phi\left(S^{2} x\right), \\
& \vdots \\
& (1-\alpha) p\left(S^{n-1} x, S^{n} x\right)+\phi\left(S^{n+1} x\right) \leq \phi\left(S^{n} x\right) .
\end{aligned}
$$

Adding these inequalities, we have

$$
(1-\alpha)\left\{p(x, S x)+p\left(S x, S^{2} x\right)+\cdots+p\left(S^{n-1} x, S^{n} x\right)\right\} \leq \phi(S x)-\phi\left(S^{n+1} x\right) .
$$

Since $\left\{\phi\left(S^{n} x\right)\right\}$ is a decreasing sequence and bounded below, we see that there exists $s=$ $\lim _{n \rightarrow \infty} \phi\left(S^{n} x\right)$. Thus we have, for any $n \in \mathbb{N}$,

$$
\begin{aligned}
(1-\alpha) p\left(x, S^{n} x\right) & \leq(1-\alpha)\left\{p(x, S x)+p\left(S x, S^{2} x\right)+\cdots+p\left(S^{n-1} x, S^{n} x\right)\right\} \\
& \leq \phi(S x)-\phi\left(S^{n+1} x\right) \\
& \leq \phi(S x)-s<\infty .
\end{aligned}
$$

Then $\left\{p\left(x, S^{n} x\right)\right\}$ is bounded. Furthermore, from (3.21) we have

$$
(1-\alpha) p(S x, x)+\phi\left(S^{2} x\right) \leq \phi(S x), \quad \forall x \in X
$$

As in the above argument, we have, for any $n \in \mathbb{N}$,

$$
(1-\alpha) p\left(S^{n} x, x\right) \leq \phi(S x)-s<\infty .
$$

Then $\left\{p\left(S^{n} x, x\right)\right\}$ is bounded. Replacing $x$ by $S^{n} x$ in (3.19), we have, for any $n \in \mathbb{N}$,

$$
\begin{aligned}
& \alpha\left(p\left(S^{n+1} x, y\right)+p\left(y, S^{n+1} x\right)\right) \\
& \quad+(1-\alpha)\left(p\left(S^{n} x, y\right)+p\left(y, S^{n} x\right)\right)+\phi(S y) \leq \phi(y), \quad \forall y \in X .
\end{aligned}
$$

Applying a Banach limit $\mu$ to the both sides of this inequality, we have

$$
\begin{aligned}
& \alpha\left(\mu_{n} p\left(S^{n+1} x, y\right)+\mu_{n} p\left(y, S^{n+1} x\right)\right) \\
& \quad+(1-\alpha)\left(\mu_{n} p\left(S^{n} x, y\right)+\mu_{n} p\left(y, S^{n} x\right)\right)+\phi(S y) \leq \phi(y), \quad \forall y \in X .
\end{aligned}
$$

Since $\mu_{n} p\left(S^{n+1} x, y\right)+\mu_{n} p\left(y, S^{n+1} x\right)=\mu_{n} p\left(S^{n} x, y\right)+\mu_{n} p\left(y, S^{n} x\right)$, we get

$$
\mu_{n}\left(p\left(S^{n} x, y\right)+p\left(y, S^{n} x\right)\right)+\phi(S y) \leq \phi(y), \quad \forall y \in X .
$$

By Theorem 3.1, $S$ has a unique fixed point $x_{0}$ in $\{x \in X: \phi(x)<\infty\}$ such that $\phi\left(x_{0}\right)=$ $\inf _{u \in X} \phi(u)$ and $x_{0}=\lim _{k \rightarrow \infty} S^{k} z$ for all $z \in X$ with $\phi(z)<\infty$.

\section{Existence theorems for set-valued mappings}

Using $w$-distances, we have the following existence theorem for set-valued mappings in a complete metric space. Let $(X, d)$ be a metric space and let $P(X)$ be the class of all nonempty subsets of $X$. A mapping of $X$ into $P(X)$ is called a set-valued mapping, or a multi-valued mapping. 
Theorem 4.1 Let $(X, d)$ be a complete metric space, let $p \in W(X)$, and let $\left\{x_{n}\right\}$ be a sequence in $X$ such that $\left\{p\left(x_{n}, w\right)\right\}$ and $\left\{p\left(w, x_{n}\right)\right\}$ are bounded for some $w \in X$. Let $\mu$ be a mean on $\ell^{\infty}$ and let $\phi: X \rightarrow(-\infty, \infty]$ be a proper, bounded below, and lower semicontinuous function. Let $S: X \rightarrow P(X)$ be a set-valued mapping such that for each $x \in X$, there exists $y \in$ Sx satisfying

$$
\mu_{n} p\left(x_{n}, x\right)+\mu_{n} p\left(x, x_{n}\right)+\phi(y) \leq \phi(x)
$$

Then there exists $x_{0} \in X$ such that

(1) $x_{0} \in S x_{0}$;

(2) $\phi\left(x_{0}\right)=\inf _{y \in X} \phi(y)$;

(3) for any $z \in X$ with $\phi(z)<\infty$, there exists a sequence $\left\{z_{m}\right\} \subset X$ such that $z_{m+1} \in S z_{m}$, $m \in \mathbb{N} \cup\{0\}$ and $z_{m} \rightarrow x_{0}$ as $m \rightarrow \infty$.

Proof For each $z_{1}=z \in X$ with $\phi(z)<\infty$, there exists $z_{2} \in S z_{1}$ such that

$$
\mu_{n} p\left(x_{n}, z_{1}\right)+\mu_{n} p\left(z_{1}, x_{n}\right) \leq \phi\left(z_{1}\right)-\phi\left(z_{2}\right) .
$$

Repeating this process, we get a sequence $\left\{z_{m}\right\}$ in $X$ such that $z_{m+1} \in S z_{m}$ and

$$
\mu_{n} p\left(x_{n}, z_{m}\right)+\mu_{n} p\left(z_{m}, x_{n}\right) \leq \phi\left(z_{m}\right)-\phi\left(z_{m+1}\right)
$$

for each $m \in \mathbb{N}$. Clearly, $\left\{\phi\left(z_{m}\right)\right\}$ is a decreasing sequence which is bounded below. Hence $\lim _{m \rightarrow \infty} \phi\left(z_{m}\right)$ exists. Put $s=\lim _{m \rightarrow \infty} \phi\left(z_{m}\right)$. We have from (4.2)

$$
\lim _{m \rightarrow \infty} \mu_{n} p\left(x_{n}, z_{m}\right)=0 \quad \text { and } \quad \lim _{m \rightarrow \infty} \mu_{n} p\left(z_{m}, x_{n}\right)=0 .
$$

We have, for any $m, n \in \mathbb{N}$,

$$
p\left(z_{m}, z_{m+1}\right) \leq p\left(z_{m}, x_{n}\right)+p\left(x_{n}, z_{m+1}\right) .
$$

Since $\mu$ is a mean on $\ell^{\infty}$, we have, for any $m \in \mathbb{N}$,

$$
\begin{aligned}
p\left(z_{m}, z_{m+1}\right) & \leq \mu_{n} p\left(z_{m}, x_{n}\right)+\mu_{n} p\left(x_{n}, z_{m+1}\right) \\
& \leq \phi\left(z_{m}\right)-\phi\left(z_{m+1}\right)+\phi\left(z_{m+1}\right)-\phi\left(z_{m+2}\right) \\
& =\phi\left(z_{m}\right)-\phi\left(z_{m+2}\right) .
\end{aligned}
$$

We have from (4.4), for any $l, m \in \mathbb{N}$ with $m>l$,

$$
\begin{aligned}
p\left(z_{l}, z_{m}\right) \leq & p\left(z_{l}, z_{l+1}\right)+p\left(z_{l+1}, z_{l+2}\right)+\cdots+p\left(z_{m-1}, z_{m}\right) \\
\leq & \phi\left(z_{l}\right)-\phi\left(z_{l+2}\right)+\phi\left(z_{l+1}\right)-\phi\left(z_{l+3}\right) \\
& +\cdots+\phi\left(z_{m-1}\right)-\phi\left(z_{m+1}\right) \\
= & \phi\left(z_{l}\right)+\phi\left(z_{l+1}\right)-\phi\left(z_{m}\right)-\phi\left(z_{m+1}\right) \\
\leq & \phi\left(z_{l}\right)+\phi\left(z_{l+1}\right)-s-s
\end{aligned}
$$




$$
\begin{aligned}
& \leq \phi\left(z_{l}\right)+\phi\left(z_{l}\right)-s-s \\
& =2 \phi\left(z_{l}\right)-2 s
\end{aligned}
$$

and $2 \phi\left(z_{l}\right)-2 s \rightarrow 0$ as $l \rightarrow \infty$. We see from Lemma 2.1 that $\left\{z_{m}\right\}$ is a Cauchy sequence in $X$. Since $X$ is complete, there exists a point $x_{0} \in X$ such that $\lim _{m \rightarrow \infty} z_{m}=x_{0}$. We know from the definition of $p$ that, for any $n \in \mathbb{N}, y \mapsto p\left(x_{n}, y\right)$ is lower semicontinuous. Using this and following the technique of [7], we have, for any $n \in \mathbb{N}$,

$$
p\left(x_{n}, x_{0}\right) \leq \liminf _{m \rightarrow \infty} p\left(x_{n}, z_{m}\right)
$$

and hence

$$
\mu_{n} p\left(x_{n}, x_{0}\right) \leq \mu_{n}\left(\liminf _{m \rightarrow \infty} p\left(x_{n}, z_{m}\right)\right)
$$

On the other hand, we have from (4.5), for any $l, k, n \in \mathbb{N}$ with $m>l$,

$$
\begin{aligned}
p\left(x_{n}, z_{m}\right) & \leq p\left(x_{n}, z_{l}\right)+p\left(z_{l}, z_{m}\right) \\
& \leq p\left(x_{n}, z_{l}\right)+2 \phi\left(z_{l}\right)-2 s
\end{aligned}
$$

and hence

$$
\limsup _{m \rightarrow \infty} p\left(x_{n}, z_{m}\right) \leq p\left(x_{n}, z_{l}\right)+2 \phi\left(z_{l}\right)-2 s
$$

Applying $\mu$ to both sides of the inequality, we have

$$
\mu_{n}\left(\limsup _{m \rightarrow \infty} p\left(x_{n}, z_{m}\right)\right) \leq \mu_{n} p\left(x_{n}, z_{l}\right)+2 \phi\left(z_{l}\right)-2 s
$$

Letting $l \rightarrow \infty$, we get

$$
\mu_{n}\left(\limsup _{m \rightarrow \infty} p\left(x_{n}, z_{m}\right)\right) \leq \liminf _{l \rightarrow \infty} \mu_{n} p\left(x_{n}, z_{l}\right) .
$$

We have from (4.3), (4.6), and (4.7)

$$
\begin{aligned}
\mu_{n} p\left(x_{n}, x_{0}\right) & \leq \mu_{n}\left(\liminf _{m \rightarrow \infty} p\left(x_{n}, z_{m}\right)\right) \\
& \leq \mu_{n}\left(\limsup _{m \rightarrow \infty} p\left(x_{n}, z_{m}\right)\right) \\
& \leq \liminf _{m \rightarrow \infty} \mu_{n} p\left(x_{n}, z_{m}\right) \\
& =\lim _{m \rightarrow \infty} \mu_{n} p\left(x_{n}, z_{m}\right)=0 .
\end{aligned}
$$

This implies that

$$
\mu_{n} p\left(x_{n}, x_{0}\right)=0
$$


Doing the same argument as above for each $y_{1}=y \in X$ with $\phi(y)<\infty$, we can construct a sequence $\left\{y_{m}\right\}$ in $X$ such that $\left\{\phi\left(y_{m}\right)\right\}$ is a decreasing sequence, $\lim _{m \rightarrow \infty} y_{m}=y_{0}$ for some $y_{0} \in X$, and $\mu_{n} p\left(x_{n}, y_{0}\right)=0$. We show that $x_{0}=y_{0}$. We have, for any $m, n \in \mathbb{N}$,

$$
p\left(z_{m}, x_{0}\right) \leq p\left(z_{m}, x_{n}\right)+p\left(x_{n}, x_{0}\right) .
$$

Then, we have

$$
\begin{aligned}
p\left(z_{m}, x_{0}\right) & \leq \mu_{n} p\left(z_{m}, x_{n}\right)+\mu_{n} p\left(x_{n}, x_{0}\right) \\
& =\mu_{n} p\left(z_{m}, x_{n}\right) .
\end{aligned}
$$

Furthermore, we have, for any $m, n \in \mathbb{N}$,

$$
p\left(z_{m}, y_{0}\right) \leq p\left(z_{m}, x_{n}\right)+p\left(x_{n}, y_{0}\right)
$$

and hence

$$
\begin{aligned}
p\left(z_{m}, y_{0}\right) & \leq \mu_{n} p\left(z_{m}, x_{n}\right)+\mu_{n} p\left(x_{n}, y_{0}\right) \\
& =\mu_{n} p\left(z_{m}, x_{n}\right) .
\end{aligned}
$$

We know from (4.3) that $\mu_{n} p\left(z_{m}, x_{n}\right) \rightarrow 0$ as $m \rightarrow \infty$. Therefore, from (4.9), (4.10), and Lemma $2.1 x_{0}=y_{0}$. Since $\phi$ is lower semicontinuous,

$$
\phi\left(x_{0}\right)=\phi\left(y_{0}\right) \leq \liminf _{m \rightarrow \infty} \phi\left(y_{m}\right)=\lim _{m \rightarrow \infty} \phi\left(y_{m}\right)=\inf _{m \in \mathbb{N}} \phi\left(y_{m}\right) \leq \phi\left(y_{1}\right) .
$$

Since $y_{1}$ is any point of $X$ with $\phi\left(y_{1}\right)<\infty$, we have

$$
\phi\left(x_{0}\right)=\inf _{y \in X} \phi(y)
$$

Using (4.1), we have $u_{0} \in X$ such that $u_{0} \in S x_{0}$ and

$$
\mu_{n} p\left(x_{n}, x_{0}\right)+\mu_{n} p\left(x_{0}, x_{n}\right) \leq \phi\left(x_{0}\right)-\phi\left(u_{0}\right) .
$$

Furthermore, repeating this process, we have $v_{0} \in X$ such that $v_{0} \in S u_{0}$ and

$$
\mu_{n} p\left(x_{n}, u_{0}\right)+\mu_{n} p\left(u_{0}, x_{n}\right) \leq \phi\left(u_{0}\right)-\phi\left(v_{0}\right) .
$$

Using (4.11), we have

$$
\mu_{n} p\left(x_{n}, u_{0}\right)+\mu_{n} p\left(u_{0}, x_{n}\right) \leq \phi\left(u_{0}\right)-\phi\left(v_{0}\right) \leq \phi\left(u_{0}\right)-\phi\left(x_{0}\right) .
$$

Then we have from (4.12) and (4.13)

$$
\mu_{n} p\left(x_{n}, u_{0}\right)+\mu_{n} p\left(u_{0}, x_{n}\right)+\mu_{n} p\left(x_{n}, u_{0}\right)+\mu_{n} p\left(u_{0}, x_{n}\right) \leq 0 .
$$


This implies that

$$
\mu_{n} p\left(x_{n}, u_{0}\right)=0
$$

Since $p\left(z_{m}, u_{0}\right) \leq p\left(z_{m}, x_{n}\right)+p\left(x_{n}, u_{0}\right)$ for $m, n \in \mathbb{N}$, we have

$$
\begin{aligned}
p\left(z_{m}, u_{0}\right) & \leq \mu_{n} p\left(z_{m}, x_{n}\right)+\mu_{n} p\left(x_{n}, u_{0}\right) \\
& =\mu_{n} p\left(z_{m}, x_{n}\right)
\end{aligned}
$$

We know from (4.3) that $\mu_{n} p\left(z_{m}, x_{n}\right) \rightarrow 0$ as $m \rightarrow \infty$. Therefore, from (4.9), (4.14), and Lemma $2.1 x_{0}=u_{0}$. Since $u_{0} \in S x_{0}$, we have $x_{0} \in S x_{0}$. This completes the proof.

Let $(X, d)$ be a metric space. Then $S: X \rightarrow P(X)$ is called a multi-valued weakly Picard operator [10] if for each $x \in X$ and each $y \in S x$, there exists a sequence $\left\{x_{n}\right\}$ in $X$ such that

(1) $x_{0}=x, x_{1}=y$

(2) $x_{n+1} \in S x_{n}, n \in \mathbb{N} \cup\{0\}$;

(3) $\left\{x_{n}\right\}$ is convergent and its limit is a fixed point of $S$.

Using Theorem 4.1, we can get the following result proved by Takahashi et al. [7].

Theorem 4.2 ([7]) Let $(X, d)$ be a complete metric space, let $p \in W_{0}(X)$ and let $\left\{x_{n}\right\}$ be a sequence in $X$ such that $\left\{p\left(x_{n}, x\right)\right\}$ is bounded for some $x \in X$. Let $\mu$ be a mean on $\ell^{\infty}$ and let $\psi: X \rightarrow(-\infty, \infty)$ be a bounded below and lower semicontinuous function. Let $T: X \rightarrow$ $P(X)$ be a set-valued mapping such that for each $u \in X$, there exists $v \in T u$ satisfying

$$
\mu_{n} p\left(x_{n}, u\right)+\psi(v) \leq \psi(u)
$$

Then $T$ is a multi-valued weakly Picard operator.

Proof Putting $S=T$ and $\phi=2 \psi$ in Theorem 4.1, we see that, for each $x \in X$, there exists $y \in T x$ such that

$$
2 \mu_{n} p\left(x_{n}, x\right)+2 \psi(y) \leq 2 \psi(x)
$$

and hence

$$
\mu_{n} p\left(x_{n}, x\right)+\psi(y) \leq \psi(x)
$$

For each $x \in X$ and each $y \in T x$, put $u_{0}=x$ and $u_{1}=y$. Then we can take $u_{2} \in T u_{1}$ such that

$$
\mu_{n} p\left(x_{n}, u_{1}\right)+\psi\left(u_{2}\right) \leq \psi\left(u_{1}\right)
$$

Repeating this process, we get a sequence $\left\{u_{m}\right\}$ in $X$ such that $u_{m+1} \in T u_{m}$ and

$$
\mu_{n} p\left(x_{n}, u_{m}\right) \leq \psi\left(u_{m}\right)-\psi\left(u_{m+1}\right)
$$

for each $m \in \mathbb{N} \cup\{0\}$. Thus we have the desired result from Theorem 4.1. 
Competing interests

The authors declare that they have no competing interests.

\section{Authors' contributions}

All authors contributed equally and significantly in writing this article. All authors read and approved the final manuscript.

\section{Author details}

${ }^{1}$ Faculty of Economics, Keio University, Mita 2-15-45, Minato-ku, Tokyo, 108-8345, Japan. ${ }^{2}$ Center for Fundamental Science, Kaohsiung Medical University, Kaohsiung, 80702, Taiwan. ${ }^{3}$ Keio Research and Education Center for Natural Sciences, Keio University, Kouhoku-ku, Yokohama, 223-8521, Japan. ${ }^{4}$ Department of Mathematical and Computing Sciences, Tokyo Institute of Technology, Ookayama, Meguro-ku, Tokyo, 152-8552, Japan. ${ }^{5}$ Center for General Education, China Medical University, Taichung, 40402, Taiwan.

\section{Acknowledgements}

The second author was partially supported by Grant-in-Aid for Scientific Research No. 15K04906 from Japan Society for the Promotion of Science. The fourth author was partially supported by the grant MOST 103-2923-E-039-001-MY3.

Received: 21 August 2015 Accepted: 9 March 2016 Published online: 22 March 2016

\section{References}

1. Hasegawa, K, Komiya, T, Takahashi, W: Fixed point theorems for general contractive mappings in metric spaces and estimating expressions. Sci. Math. Jpn. 74, 15-27 (2011)

2. Caristi, J: Fixed point theorems for mappings satisfying inwardness conditions. Trans. Am. Math. Soc. 215, 241-251 (1976)

3. Chuang, C-S, Lin, L-J, Takahashi, W: Fixed point theorems for single-valued and set-valued mappings on complete metric spaces. J. Nonlinear Convex Anal. 13, 515-527 (2012)

4. Kada, O, Suzuki, T, Takahashi, W: Nonconvex minimization theorems and fixed point theorems in complete metric spaces. Math. Jpn. 44, 381-391 (1996)

5. Ekeland, I: Nonconvex minimization problems. Bull. Am. Math. Soc. 1, 443-474 (1979)

6. Takahashi, W: Existence theorems generalizing fixed point theorems for multivalued mappings. In: Fixed Point Theory and Applications, Marseille, 1989. Pitman Res. Notes Math. Ser., vol. 252, pp. 397-406. Longman, Harlow (1991)

7. Takahashi, W, Wong, N-C, Yao, J-C: Fixed point theorems for general contractive mappings with $w$-distances in metric spaces. J. Nonlinear Convex Anal. 14, 637-648 (2013)

8. Takahashi, W: Nonlinear Functional Analysis. Yokohoma Publishers, Yokohoma (2000)

9. Shioji, N, Suzuki, T, Takahashi, W: Contractive mappings, Kannan mappings and metric completeness. Proc. Am. Math. Soc. 126, 3117-3124 (1998)

10. Rus, IA, Petrusel, A, Sintamarrian, A: Data dependence of the fixed point set of some multivalued weakly Picard operators. Nonlinear Anal. 52, 1947-1959 (2003)

\section{Submit your manuscript to a SpringerOpen ${ }^{\circ}$ journal and benefit from:}

- Convenient online submission

Rigorous peer review

- Immediate publication on acceptance

- Open access: articles freely available online

- High visibility within the field

- Retaining the copyright to your article 